\title{
sciendo
}

\section{Are Teams whose Players are More Committed to the Team More Resilient? The Role of Intra-Group Conflict}

\author{
by \\ Miguel A. López-Gajardoํㅜ, Tomás García-Calvo, Inmaculada González-Ponce², \\ Abril Cantú-Berrueto ${ }^{3}$, Mládosich Parma-Aragón ${ }^{3}$, José Moncada-Jiménez $z^{4}$ \\ Alejandro Salicetti-Fonseca ${ }^{4}$, Juan M. Tassi ${ }^{1}$, Francisco M. Leo ${ }^{5}$
}

The study aimed to analyze the relationship between commitment to the team and team resilience factors (characteristics of resilience and vulnerability under pressure), and to examine whether the task and social intra-group conflict act as mediators between commitment to the team and team resilience factors. One hundred seventy (170) male soccer players (16-38 years; $M=18.35 ; S D=4.72)$ of the national teams of Argentina, Costa Rica, and Mexico participated in the study. The path analytic model was used to test mediating pathways. First, the results revealed that commitment to the team was positively related to characteristics of resilience and negatively to vulnerability under pressure. Second, bootstrap mediation analysis showed that athletes' perceptions of the task and social intra-group conflict mediated the association between their perception of commitment to the team and team resilience factors. Findings provide initial evidence for a link between commitment to the team and team resilience in national teams and also suggest that intra-group conflict can improve the association between commitment to the team and team resilience. Therefore, the main conclusion of this study is that practioners should promote players' commitment to the team and avoid intra-group conflicts within teams to have a resilient team that copes with problems more easily.

Key words: commitment to the team, intra-group conflict, group dynamics, team resilience, sport psychology.

\section{Introduction}

During the season or a match, sports teams can go through some difficult moments. The teams' capacity to face them, resist them, and to overcome difficult situations, known as team resilience (Morgan et al., 2015), can determine the achievement of a good performance (Sarkar and Fletcher, 2014). The isolated involvement of team players is not enough to reverse these moments of vulnerability, the whole team's commitment is needed to improve collective functioning in these situations (Morgan et al., 2013). The degree of commitment perception of each player to the team can determine the entire team's predisposition and involvement to overcome difficult situations and to reduce the weakness under pressure (Morgan et al., 2015).

Although commitment to the team has been identified as one of the variables to explain levels of team resilience (Morgan et al., 2013), to our knowledge, there are hardly any studies which have tried to explain this relationship. Therefore, considering that team resilience is one of the psychological constructs which has been positively related with an increase in team performance (Meneghel et al., 2016; Morgan et al., 2016) and a key determinant of optimal collective functioning (Decroos et al., 2017), it would be

1 - Faculty of Sport Sciences, University of Extremadura, Cáceres, Spain.

2 - Faculty of Education, University of Extremadura, Badajoz, Spain.

3 - Mexican Soccer Federation, San Mateo Otzacatipan, Mexico.

4 - University of Costa Rica, San José, Costa Rica.

5 - Faculty of Teacher Training, University of Extremadura, Cáceres, Spain. 
interesting to determine a possible antecedent which may help explain the levels of team resilience in team sports.

\section{Team resilience}

Team resilience was defined as "a dynamic, psychosocial process which protects a group of individuals from the potential negative effect of the stressors they collectively encounter" (Morgan et al., 2013). To examine this construct in greater depth, Morgan et al. (2013) proposed a framework to profile the resilient characteristics of elite sports teams based on the opinion of highperformance athletes. Specifically, team resilience is made up of a series of features which can be grouped in two large factors (Decroos et al., 2017; Gorgulu et al., 2018, López-Gajardo et al., 2021): (a) characteristics of resilience or the team's ability to overcome adversity; and (b) vulnerability under pressure, which is considered as the team's inability to overcome difficult situations. These two factors emanate from the four principal dimensions which have been identified to represent the construct of team resilience (Morgan et al., 2013): (a) group structure, referring to the communication among players, the established roles within a group and the shared vision in tense moments; (b) knowledge which refers to the groups' improvement after suffering a setback; c) social capital which refers to the emotional links among teammates; and d) collective efficacy which comprises players' perceptions as a team to face competition.

Within each of these dimensions there are different variables which are considered promoters of team resilience. Specifically, this study focused on the variables underlying the category of collective efficacy. Among them there is the commitment to the team, which was cataloged in a Morgan et al.'s (2013) study as one of the facilitating variables of team resilience because it promoted a greater predisposition in the whole group to face competition confidently. Commitment to the team can be defined as a person's loyalty towards an organization or a group (Meyer and Alien, 1991). This variable has been previously identified as an essential factor to achieve a good resilient profile in team sports (Holt and Dunn, 2004), and to be capable of facing problems and vulnerability moments (Dimmock et al., 2005; Zurita-Ortega et al., 2018). In fact, commitment to the team has been used as a key strategy in interventions to improve the characteristics of resilience and to reduce the vulnerability under pressure (Morgan et al., 2019). Therefore, commitment to the team could improve team resilience in collective sports. When players show an unconditional predisposition towards the team, with great engagement and commitment, they will be more willing to seek solutions or exceed themselves to serve the group and overcome adversity.

\section{The present study}

Even though Morgan et al. (2013) established and analyzed the characteristics which make up team resilience, there are hardly any quantitative studies which have corroborated the relationship between facilitating variables (i.e., commitment to the team) and resilience (Glantz and Sloboda, 2002; Luthar et al., 2000; Morgan et al., 2019; Wagstaff et al., 2017). In fact, some researchers have pointed out the need to deepen our knowledge of different protective factors (i.e., stressful and adaptive) of team resilience (Morgan et al., 2013, 2019). Specifically, in the sports context, Morgan et al. (2017) pointed out to the importance of increasing knowledge of the contextual enablers that promote team resilience, which would be a great advance for study of team resilience (Morgan et al., 2013, 2019). Therefore, in line with the conceptual framework of team resilience and prior studies which have provided descriptive information about the factors that can help teams to resist adverse situations (Decross et al., 2017; Morgan et al., 2013), the first aim of this study was to examine the relationship between commitment to the team and team resilience. Based on this objective and the existing scientific literature, the following hypothesis was formulated:

Hypothesis 1: Commitment to the team will be positively related to the characteristics of resilience, and negatively associated to vulnerability under pressure.

Following Fletcher and Sarkar's (2013) affirmations, team resilience is related to other variables which can hinder the influence of variables that protect team resilience (i.e., commitment to the team), preventing their protective action. Thus, Morgan et al. (2013) indicated the importance of analyzing stressful factors which can alter the effect of protective factors (i.e., commitment to the team) of team 
resilience. Decross et al. (2107) showed how teams conflicts, defined as "a dynamic process that occurs between interdependent parties as they experience negative emotional reactions to perceived disagreements and interference with the attainment of their goals" (Barki and Hartwick, 2004), could be negatively associated with team resilience. Specifically, they found a negative relationship between intra-group conflicts and the characteristics of resilience and a positive relationship between intra-group conflicts and vulnerability under pressure (Decross et al., 2017). Therefore, considering that intra-group conflicts are traditionally related to the worsening of collective functioning (Fletcher et al., 2012; Leo et al., 2015; Paradis et al., 2014; Tabei et al., 2012), we expected that when teams were in difficult situations, previous intra-group conflicts could worsen the situation (Decross et al., 2017).

Also, considering the negative link between the levels of commitment and intragroup conflicts found in the organizational context (Bishop et al., 2000; Lee et al., 2018), intragroup conflicts could function as a mediating variable in the relationship between commitment to the team and team resilience. Specifically, commitment to the team was negatively related to two intra-group conflict factors (Lee et al., 2018): task conflicts, i.e., cognitive problems about disagreements between team members concerning objectives, strategies and opinions, and social conflicts, i.e., emotional tension encompassed within an atmosphere of negative emotions (Paradis et al., 2014). In this sense, the second objective of the study was to analyze whether intra-group conflicts could mediate the relationship between commitment to the team and team resilience. Thus, following this objective and previous studies, the next hypothesis was formulated:

Hypothesis 2: Intra-group conflict (task and social) will be a mediator in the relationship between commitment to the team and team resilience.

\section{Methods}

\section{Participants}

The study participants included 170 male soccer players, with an age range between 14 and 38 years $(M=18.35, S D=4.71)$. Athletes were team members of eight national teams, of which seven were youth teams (from U16 to U21) and one elite team $(\mathrm{n}=1)$, from Argentina $(\mathrm{n}=2)$, Costa Rica $(\mathrm{n}$ $=2)$, and Mexico $(n=4)$. On average, players had represented their countries for a total of 6.62 times $(\mathrm{SD}=6.58)$, and 20 players were participating in their first callup to the national team.

\section{Instruments}

Commitment to the team. To measure athletes' perceptions of commitment to the team in the season, a Spanish version of the KUT Commitment Scale (KUT: Klein et al., 2014) was used. This scale has a total of four items (e.g., "How committed are you to the team"). Players responded to all items on a 5-point Likert-type scale ranging from 1 (strongly disagree) to 5 (strongly agree). This scale was adaptated to the Spanish language according to the strategy proposed by Hambleton (2005). First, concerning the Content Validity Index (Lynn, 1986), all the items were translated from English into Spanish by four experts on sport psychology and using instrument validations. Each of the experts' contributions were assessed and agreed upon, and the final content for the questionnaire was selected. Second, a bilingual translator translated it back to the English language, obtaining a high degree of agreement between both versions. A Confirmatory Factor Analysis (CFA) was run to test the validity, demonstrating an adequate model fit to the data, i.e., scores greater than .90 for the incremental indexes of CFI and TLI (Bentler and Bonett, 1980; Schumacher and Lomax, 1996) and values less than .06 for the RMSEA and .80 for the SRMR (Hu and Bentler, 1999) were considered acceptable: $\chi 2=2.822, \mathrm{df}=$ $2, \mathrm{p}=.243, \mathrm{CFI}=.99, \mathrm{TLI}=.98, \mathrm{RMSEA}=.04,95 \%$ CI $[.00, .15]$, SRMR $=.02$. Regarding the factor loadings of the global factor, adequate values were obtained in all cases $(\lambda=.61-.90)$. In addition, commitment to the team showed adequate values of internal consistency $(\alpha=.90, \omega$ $=.92$; Knapp and Mueller, 2010; Nunnally and Bernstein, 1994).

Intra-group conflict. To measure athletes' perceptions of intra-group conflict during the season, the Spanish version of the Intragroup Team Conflict Scale (ITCS; Tekleab et al., 2009) developed by Leo et al. (2015) was used. This instrument has a total of six items divided into two factors: task conflict (3 items, e.g., "How frequently were there conflicts about ideas on 
your team?") and social conflict (3 items, e.g., "How frequently was there emotional conflict among members on your team?"). Players responded to all items on a seven-point scale ranging from 1 (never) to 7 (always). A CFA was performed to check the validity of the structure, showing an adequate model fit, $\chi 2=14.468, \mathrm{df}=8$, $\mathrm{p}=.070, \mathrm{CFI}=.97, \mathrm{TLI}=.95, \mathrm{RMSEA}=.06,95 \% \mathrm{CI}$ $[.00, .11]$, SRMR $=.03$. Factor loading values were adequate for the task $(\lambda=.51-.74)$ and social conflict $(\lambda=.54-.81)$. Moreover, each dimension demonstrated adequate levels of internal consistency (task conflict, $\alpha=.72, \omega=.70$; social conflict, $\alpha=.77, \omega=.73$; Knapp and Mueller, 2010; Nunnally and Bernstein, 1994).

Team Resilience. To measure athletes' perceptions of team resilience, the Spanish version of the Characteristics of Resilience in Sports Teams Inventory (CREST; Decross et al., 2017) developed by López-Gajardo et al. (2021) was used. This instrument uses the stem: "In the last stage, when my team was under pressure...", which is then followed by 20 items corresponding to two factors: characteristics of resilience (12 items, e.g., "I felt that I could count on other members of the team") and vulnerability under pressure (8 items, e.g., "the team did not believe in its ability to withstand pressure"). Players responded to all items on a 7-point Likert-type scale ranging from 1 (strongly disagree) to 7 (strongly agree). A CFA was conducted to check the validity, showing an adequate model fit, $\chi 2=$ 265.197, $\mathrm{df}=169, \mathrm{p}<.001, \mathrm{CFI}=.92$, TLI $=.92$, RMSEA $=.05,95 \%$ CI $[.04, .06]$, SRMR $=.05$. Factor loading values were adequate for characteristics of resilience $(\lambda=.51-.72)$ and vulnerability under pressure $(\lambda=.55-.80)$. Moreover, internal consistency values were adequate (characteristics of resilience, $\alpha=.90, \omega=.85$; vulnerability under pressure, $\alpha=.86, \omega=.81$; Knapp and Mueller, 2010; Nunnally and Bernstein, 1994).

\section{Procedures}

The study received the Bioethics Committee's approval from the first author's university (239/2019). All participants were treated according to the American Psychological Association's ethical guidelines (2019) regarding consent, confidentiality, and anonymity of responses. A cross-sectional design was used. The questionnaires were supplied during one of the national team concentrations during the sports season.
The main researcher contacted the sport psychologist of the national teams to explain the study's objectives and to ask for the teams' participation in the project. Upon approval to participate in the study, the research assistants provided each individual with a letter of information and a consent form (to be signed by the participant and, if under the age of 16 , by a parent/guardian). Participants completed the questionnaires in the locker room before a training session. The questionnaires were completed individually, typically within 15-20 min, in the absence of their coach, supervised by the research assistants, and under no distracting conditions (This study was conduced together with another study examining different group dynamic variables in sport.).

Data analysis

All statistical analyses were performed with Mplus version 7.3 (Muthén and Muthén, 1998-2017). In the main analyses, structural equation modelling (SEM) was used to test mediating pathways. Indirect effects were tested using the bias-corrected bootstrap method (10000 samples with $95 \%$ bias-corrected confidence intervals (CIs); MacKinnon et al., 2004) with the maximum likelihood procedure (ML; bootstrapping is unavailable when using MLR estimation). This currently represents the most effective way to identify mediated relationships, given the asymmetry of their theoretical distributions (Cheung and Lau, 2008). If the CI did not include "zero," the mediated relationship was considered to significantly differ from zero (Intraclass correlation coefficients for each subscale were not above .10, indicating that the between-team variance was low (Hox, 2010). Furthermore, the number of teams was very low $(\mathrm{k}=8)$, which is problematic for more complex multilevel analyses. As recommended by McNeish and Stapleton (2016), we used fixed effects modelling to address the issue of nonindependence by partialling out the effect of group membership. This involved creating seven dummy variables based on group membership ( $\mathrm{k}$ - 1) and including them in each mediation model.).

\section{Results}

\section{Descriptive statistics}

Table 1 shows the means, standard 
deviations, reliability analysis, and correlations of the variables under investigation of all the participants. All scales had acceptable internal consistency $(\alpha>.70$ and $\omega>.70$; Knapp and Mueller, 2010; Nunnally and Bernstein, 1994) and correlations showed positive relationships between commitment to the team and characteristics of resilience $(r=.46)$ and negative relationships between commitment to the team and vulnerability under pressure $(r=-.31)$ and intra-group conflict factors $(r=-.24--.30)$. Furthermore, intra-group conflict factors were positively correlated with vulnerability under pressure $(r=.38-.42)$ and negatively with the characteristics of resilience $(r=-.39--.40)$.

\section{Main analysis}

SEM was used to examine the relationship between commitment to the team and team resilience, and the mediating role of intra-group conflict in the relationship between commitment to the team and team resilience in four separate models. Commitment to the team was included as an independent variable, two factors of intragroup conflict (task and social conflict) as mediators, and team resilience factors as two dependent variables (characteristics of resilience and vulnerability under pressure). Figure 1 shows the standardized results of the four models. First, the results revealed that commitment to the team showed significant negative relationships with task (path $a ; \beta=-.30, p<.001$ ) and social intragroup conflict (path $a ; \beta=-.24, p<.001$ ). Second, task and social intra-group conflicts were negatively associated with characteristics of resilience (path $b_{\text {taskconflict; } \beta} \beta=-.29, p<.001$; path $\left.b_{\text {socialconflict; }} \beta=-.30, p<.001\right)$ and positively related to vulnerability under pressure (path $b_{\text {taskconflict; }} \beta=$ $.37, p<.001$; path $b_{\text {socialconflict; } \beta} \beta=.33, p<.001$ ). Third, commitment to the team was positively related to the characteristics of resilience (path $c^{\prime} ; \beta=.37-$ $.38, p<.001)$ and negatively associated to vulnerability under pressure (path $c^{\prime} ; \beta=-.20-$ $.23, p<.001)$. Finally, there was a significant indirect effect of task and social intra-group conflict in the relationship between commitment to the team and characteristics of resilience $\left(\beta_{\text {taskconflict }}=.09, p=.006,95 \%\right.$ CI $[.03, .15]$; $\beta_{\text {socialconflict }}=.07, p=.035,95 \%$ CI $\left.[.01, .14]\right)$ and vulnerability under pressure $(\beta$ taskconflict $=.11, p=$ $.004,95 \%$ CI [-.18, -.04]; $\beta_{\text {socialconflict }}=.08, p=.026,95$ $\%$ CI $[-.15,-.01])$. Specifically, the direct positive effect of commitment to the team on the characteristics of resilience increased with the task and social conflicts' negative prediction on the characteristics of resilience. Also, the direct negative effect of commitment to the team on vulnerability under pressure increased with the task and social conflicts' positive prediction of vulnerability under pressure.

Table 1

Means, standard deviations, and bivariate correlations of the variables under investigation

\begin{tabular}{lcccccc}
\hline & $M$ & $S D$ & 1 & 2 & 3 & 4 \\
\hline $\begin{array}{lcccc}\text { 1. Commitment to the team } \\
\text { 2. Task team conflict }\end{array}$ & 4.85 & .32 & - & & & \\
3. Social team conflict & 2.19 & 1.12 & $-.30^{* *}$ & - & & \\
4. Characteristics of team resilience & 2.06 & 1.04 & $-.24^{* *}$ & $.75^{* *}$ & - & \\
5. Vulnerability under pressure & 6.11 & .63 & $.46^{* *}$ & $-.40^{* *}$ & $-.39^{* *}$ & - \\
\hline
\end{tabular}

Note. ${ }^{*} p<.05,{ }^{* *} p<.01$ 


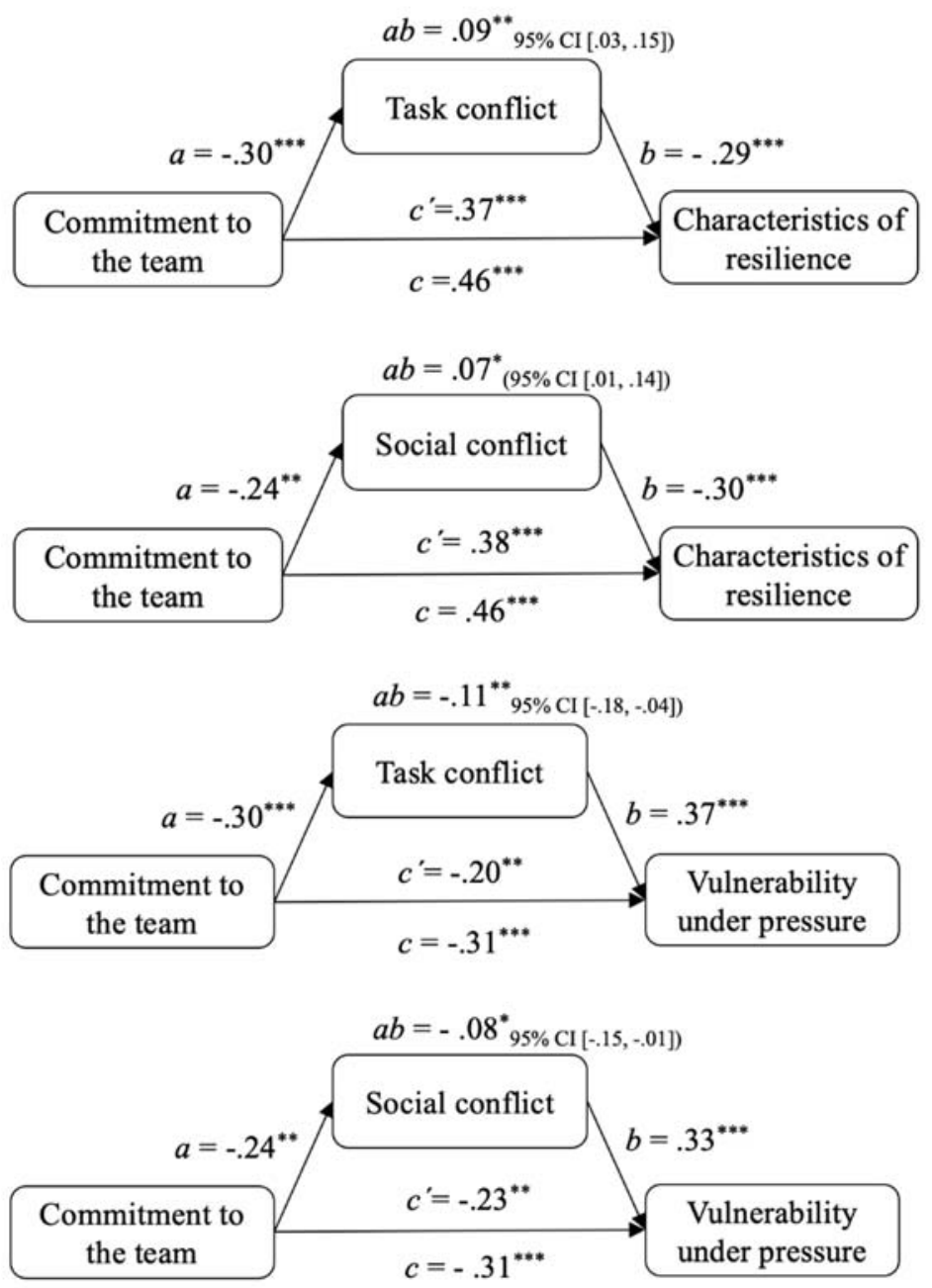

Figure 1

The mediating (indirect) effects of team conflict in the relationship between commitment to the team and team resilience

Note. ${ }^{*} p<.05,{ }^{* *} p<.01,{ }^{* * * *} p<.001 ; \mathrm{a}=\mathrm{a}$ direct path from the independent variable to the mediator; $\mathrm{b}=\mathrm{a}$ direct path from the mediator to the independent variable; $\mathrm{c}^{\prime}=\mathrm{a}$ direct path from the independent variable to the independent variable; $a b=$ an indirect effect path from the independent variable to the independent variable; $c=a$ total effect path from the independent variable to the independent variable.

\section{Discussion}

The present investigation had a dual objective: a) to analyze how commitment to the team was associated with team resilience in team sports, and b) to examine whether intra-group conflicts could mediate this relationship. In general, the results of this study were consistent with the theoretical postulates established by Morgan et al. (2013) and supported all of the hypotheses presented in this study. Specifically, higher levels of commitment to the team were associated with 
higher perceptions of team resilience. At the same time, when players perceived less task and social intra-group conflicts, team resilience's values were higher.

Analyzing each hypothesis step by step, Hypothesis 1 postulated that commitment to the team would be positively related to the characteristics of resilience, the positive factor of team resilience, and negatively to vulnerability under pressure, the negative factor of team resilience. The results supported this hypothesis, showing a positive correlation between commitment and the characteristics of the team resilience factor. Also, the correlation between the variable of commitment to the team and the negative factor of resilience, vulnerability under pressure, was negative. In team sports, there are clear indicators which show this positive association between commitment to the team and team resilience. In fact, this result confirms the theory about the characteristics and factors of team resilience elaborated by Morgan et al. (2013). Therefore, the importance attached to players' commitment when coping with stressful situations and thus, achieving higher resilience levels is remarkable (Zurita-Ortega et al., 2018). In other words, commitment to the team and team resilience are two fundamental aspects which must be developed correctly to achieve success (Holt and Dunn, 2004). Therefore, to increase team resilience when difficult situations emerge during competitions, commitment to the team should be promoted in all players so that they continue working in practice sessions and matches to achieve team goals during the season (Morgan et al., 2019).

Hypothesis 2 stated that the intra-group conflict would mediate the relationship between commitment to the team and team resilience. Firstly, the results showed that commitment to the team was negatively related with the task and social intra-group conflict. These results coincide with the findings of previous research in the organizational context (Bailey, 2000; Lee et al., 2018). Secondly, the results also showed that the task and social intra-group conflict were negatively associated to characteristics of resilience and positively to vulnerability under pressure. This finding coincides with previous investigations, showing that fewer conflicts promote higher levels of characteristics of resilience, or vice versa (Decroos et al., 2017; López- Gajardo et al., 2020). Thirdly, the association betwenn commitment to the team and characteristics of resilience and vulnerability under pressure increased via task and social intragroup conflicts. Therefore, players who perceived higher levels of commitment to the team, and also, lower task and social intra-group conflicts within the teams, showed higher levels of characteristics of resilience in the groups. Also, players who perceived lower levels of commitment to the team perceived higher conflicts in the team, which helped explain the higher levels of vulnerability under pressure. Therefore, it seems that intra-group conflict acts as a mediator between the players' commitment and their ability to cope with adversities in team sports, supporting Hypothesis 2 of the study.

\section{Theoretical and practical implications}

This work contributes to the current body of knowledge which supports the team resilience construct. In fact, it brings new knowledge and solid evidence of the framework to examine characteristics of team resilient in sports teams, previously formulated by Morgan et al. (2013). Accordingly, recommendations or proposals are drawn from the above conclusions to put them into practice in a real context of play. For example, thanks to this research, we might have observed some antecedents related to team resilience. Therefore, to increase team resilience, we recommend the technical bodies and sports psychologists to encourage commitment to the team in all the players. In addition, another key recommendation for the professionals of this sport is to pay special attention to the problems which can emerge within the group, to reduce the number of group conflicts and therefore, increase the team's ability to overcome adversities during competition. In general, the protective origin of team resilience should help teams use this characteristic as a defense against adverse circumstances, and help players use these circumstances as opportunities to develop and optimize the team's collective functioning (Morgan et al., 2013).

\section{Conclusions, limitations and future research}

The results show that to have a resilient team that copes with problems more easily, players' commitment to the team is essential. In 
turn, intra-group conflicts (task and social) can also be decisive for team resilience, as problems in team sports can make it difficult to overcome adversities and they increase vulnerability under pressure even when the players' commitment to the team is high.

Despite the study's contribution to the knowledge of team resilience, it is important to acknowledge some of the limitations of this study. First, as we used a cross-sectional design, we cannot make causal conclusions nor test fluctuations in the variables at other times of the season. However, this study was carried out with national teams of several countries that are difficult to access and can offer results in contexts associated with performance that have not been extensively analyzed. Likewise, for future studies, we recommend integrating longitudinal studies to be able to analyze the possible relationships with other interesting group variables in social investigation. Similarly, one could examine how team resilience fluctuates during a season. Therefore, keeping in mind the conceptual framework elaborated by Morgan et al. (2013), future studies should attempt to demonstrate the relationship between other variables and help explain team resilience more exhaustively.

The second limitation is the number of participants, as in the present study, the sample was small and all participants were male soccer players from national teams. Therefore, these findings do not allow considering the nesting of participants in their groups and performing a multilevel analysis, or a generalization to female soccer, to other sports, or other contexts (university, recreational, or club teams). In this case, we recommend obtaining a larger sample to perform a multilevel analysis. Previously, Morgan et al. (2015) indicated that to increase knowledge of team resilience, it must be "operationalized and evaluated differently at different levels of analysis". Also, for future works, it would be interesting to analyze team resilience variables associated with other team sports or other competitive levels, in both genders, to better generalize the results obtained.

On the other hand, for future studies, it would be useful to perform different interventions on team resilience in different contexts, to understand how sports teams function in various environmental factors and with different athletes. In fact, much more information is needed about the sociocultural influences of resilience to better understand this construct (Fletcher and Sarkar, 2013; Sarkar and Fletcher, 2014). In this sense, it would also be useful to explore team resilience taking into account individual characteristics, contextual aspects, and the structure it presents (Morgan et al., 2017).

\section{Acknowledgements:}

This work was supported by the European Regional Development Fund and, also by FSE, Government of Extremadura (Counsel of Economy and Infrastructure) [grant numbers GR18102, TA18027 and PO17012] and Government of Spain (Ministry of Education, Culture and Sports) [grant numbers FPU17/03489

\section{References}

American Psychological Association. (2019). Publication Manual of the American Psychological Association (7th ed.). American Psychological Association.

Bailey, B. (2000). Communicative behavior and conflict between African-American customers and Korean immigrant retailers in Los Angeles. Discourse and Society, 11, 86-108. https://doi.org/10.1177/0957926500011001004

Barki, H., \& Hartwick, J. (2004). Conceptualizing the construct of interpersonal conflict. International Journal of Conflict Management, 15, 216-244. https://doi.org/10.1108/eb022913

Bentler, P. M., \& Bonett, D. G. (1980). Significance tests and goodness of fit in the analysis of covariance structures. Psychological Bulletin, 88(3), 588-606. https://doi.org/10.1037/0033-2909.88.3.588

Bishop, J. W., Scott, K. D., \& Burroughs, S. M. (2000). Support, commitment, and employee outcomes in a team environment. Journal of Management, 26, 1113-1132. https://doi.org/10.1177/014920630002600603

Cheung, G. W., \& Lau, R. S. (2008). Testing mediation and suppression effects of latent variables: 
Bootstrapping with structural equation models. Organizational Research Methods, 11, 296-325. https://doi.org/10.1177/1094428107300343

Decroos, S., Lines, R. L. J., Morgan, P. B. C., Fletcher, D., Sarkar, M., Fransen, K., Boen, F., \& Broek, G. Vande. (2017). Development and validation of the Characteristics of Resilience in Sports Teams Inventory. Sport, Exercise, and Performance Psychology, 6, 158-178. https://doi.org/10.1037/spy0000089

Dimmock, J. A., Grove, J. R., \& Eklund, R. C. (2005). Reconceptualizing team identification: New dimensions and their relationship to intergroup bias. Group Dynamics: Theory, Research, and Practice, 9, 75-86. https://doi.org/10.1037/1089-2699.9.2.75

Fletcher, D., Hanton, S., Mellalieu, S. D., \& Neil, R. (2012). A conceptual framework of organizational stressors in sport performers. Scandinavian Journal of Medicine and Science in Sports, 22, 545-557. https://doi.org/10.1111/j.1600-0838.2010.01242.x

Fletcher, D., \& Sarkar, M. (2013). Psychological resilience: A review and critique of definitions, concepts, and theory. European psychologist, 18, 12-23. https://doi.org/10.1027/1016-9040/a000124

Glantz, M. D., \& Sloboda, Z. (2002). Analysis and reconceptualization of resilience. In M. D. Glantz \& J. L. Johnson (Eds.), Resilience and development (pp. 109-126). Springer.

Gorgulu, R., Senel, E., Adilogulları, İ. y Yildiz, M. (2018). An adaptation study of measurement properties for the Characteristics of Resilience in Sports Team Inventory. Education Sciences, 8, 139-153. https://doi.org/10.3390/educsci8030139

Schumacher, R. E., \& Lomax, R. G. (1996). A guide to structural equations modeling. Erl-baum.

Holt, N. L., \& Dunn, J. G. H. (2004). Toward a grounded theory of the psychosocial competencies and environmental conditions associated with soccer success. Journal of Applied Sport Psychology, 16, 199219. https://doi.org/10.1080/10413200490437949

Hox, J. J. (2010). Multilevel analysis: Techniques and applications (2nd ed.). Routledge.

Hu, L., \& Bentler, P. M. (1999). Cutoff criteria for fit indexes in covariance structure analysis: Conventional criteria versus new alternatives. Structural Equation Modeling: A Multidisciplinary Journal, 6(1), 1-55. https://doi.org/10.1080/10705519909540118

Klein, H. J., Cooper, J. T., Molloy, J. C., \& Swanson, J. A. (2014). The assessment of commitment: Advantages of a unidimensional, target-free approach. Journal of Applied Psychology, 99, 222-238. https://doi.org/10.1037/a0034751

Knapp, T. R., \& Mueller, R. O. (2010). Reliability and validity of instruments. In G. R. Hancock \& R. O. Mueller (Eds.), The reviewer's guide to quantitative methods in the social sciences (pp. 337-342). Routledge.

Lee, S., Kwon, S., Shin, S. J., Kim, M. S., \& Park, I. J. (2018). How team-level and individual-level conflict influences team commitment: A multilevel investigation. Frontiers in Psychology, 8, 2365. https://doi.org/10.3389/fpsyg.2017.02365

Leo, F. M., González-Ponce, I., Sánchez-Miguel, P. A., Ivarsson, A., \& García-Calvo, T. (2015). Role ambiguity, role conflict, team conflict, cohesion and collective efficacy in sport teams: A multilevel analysis. Psychology of Sport and 20, 6xercise, 66. https://doi.org/10.1016/J.PSYCHSPORT.2015.04.009

López-Gajardo, M.A., González-Ponce, I., García-Calvo, T. Ponce-Bordón, J.C., \& Leo, F.M. (2021). Adaptation and validation in Spanish of the Characteristics of Resilience in Sports Teams Inventory in different cultures. Journal of Sport Psychology, 30, 256-265.

Luthar, S. S., Cicchetti, D., \& Becker, B. (2000). The construct of resilience: A critical evaluation and guidelines for future work. Child Development, 71, 543-562. https://doi.org/10.1111/1467-8624.00164

Lynn, M. R. (1986). Determination and quantification of content validity. Nursing Research, 35(6), 382-386. https://doi.org/10.1097/00006199-198611000-00017

MacKinnon, D. P., Lockwood, C. M., \& Williams, J. (2004). Confidence limits for the indirect effect: Distribution of the product and resampling methods. Multivariate Behavioral Research, 39, 99-128. https://doi.org/10.1207/s15327906mbr3901_4

McNeish, D., \& Stapleton, L. M. (2016). Modeling clustered data with very few clusters. Multivariate Behavioral Research, 51, 495-518. https://doi.org/10.1080/00273171.2016.1167008

Meneghel, I., Martínez, I. M. and Salanova, M. (2016). Job-related antecedents of team resilience and improved team performance. Personnel Review, 45, 505-522. https://doi.org/10.1108/PR-04-2014-0094 
Meyer, J. P., \& Alien, N. J. (1991). A three-component conceptualization of organizational commitment. Human Resource Management Review, 1, 61-89. https://doi.org/10.1016/1053-4822(91)90011-Z

Morgan, P. B. C., Fletcher, D., \& Sarkar, M. (2013). Defining and characterizing team resilience in elite sport. Psychology of Sport and Exercise, 14, 549-559. https://doi.org/10.1016/J.PSYCHSPORT.2013.01.004

Morgan, P. B. C., Fletcher, D., \& Sarkar, M. (2019). Developing team resilience: A season-long study of psychosocial enablers and strategies in a high-level sports team. Psychology of Sport and Exercise, 45. https://doi.org/10.1016/j.psychsport.2019.101543

Morgan, P. B., Fletcher, D., \& Sarkar, M. (2017). Recent developments in team resilience research in elite sport. Current Opinion in Psychology, 16, 159-164. https://doi.org/10.1016/j.copsyc.2017.05.013

Morgan, P., Fletcher, D., \& Sarkar, M. (2015). Understanding team resilience in the world's best athletes: A case study of a rugby union World Cup winning team. Psychology of Sport and Exercise, 16, 91-100. https://doi.org/10.1016/J.PSYCHSPORT.2014.08.007

Muthén, L. K., \& Muthén, B. O. (1998-2017). Mplus User's Guide (8 thed.). Muthén and Muthén.

Nunnally, J. C., \& Bernstein. (1994). Psychometric theory. McGraw-Hill.

Paradis, K. F., Carron, A. V, \& Martin, L. J. (2014). Athlete perceptions of intra-group conflict in sport teams. Sport E Exercise Psychology Review, 10, 4-18.

Sarkar, M., \& Fletcher, D. (2014). Psychological resilience in sport performers: A review of stressors and protective factors. Journal of Sports Sciences, 32, 1419-1434. https://doi.org/10.1080/02640414.2014.901551

Schiera, A. (2005) Use and abuse of the resilience concept. Revista Investigación en Psicología, 8, 129-135.

Schumacher, R., \& Lomax, R. (1996). A beginner's guide to structural equation modeling. Lawrence Erlbaum Associates.

Tabei, Y., Fletcher, D., \& Goodger, K. (2012). The relationship between organizational stressors and athlete burnout in soccer players. Journal of Clinical Sport Psychology, 6, 146-165. https://doi.org/10.1123/jcsp.6.2.146

Tekleab, A. G., Quigley, N. R., \& Tesluk, P. E. (2009). A longitudinal study of team conflict, conflict management, cohesion, and team effectiveness. Group and Organization Management, 34, 170-205. https://doi.org/10.1177/1059601108331218

Wagstaff, C. R. D., Sarkar, M., Davidson, C. L., \& Fletcher, D. (2017). Resilience in sport: A critical review of psychosocial processes, sociocultural influences, and organizational dynamics. In C. R. D. Wagstaff (Ed.), The organizational psychology of sport (pp. 120-150). Routledge.

Zurita-Ortega, F., Chacón-Cuberos, R., Cofre-Bolados, C., Knox, E., \& Muros, J. J. (2018). Relationship of resilience, anxiety and injuries in footballers: Structural equations analysis. PloS one, 13, e0212083. https://doi.org/10.1371/journal.pone.020786

\section{Corresponding author:}

\section{Francisco M. Leo.}

Faculty of Teacher Training. University of Extremadura.

Avenida de la Universidad, s/n, C.P.: 10003, Cáceres, Spain.

Phone: +34927257050

Fax: +34 927257051 .

E-mail: franmilema@unex.es 